\title{
Decision Support System for Evaluating Existing Apartment Buildings Based on Fuzzy Signatures
}

\author{
G.I. Molnárka, L.T. Kóczy
}

\author{
Gergely I. Molnárka, László T. Kóczy \\ Széchenyi István University, Györ, \\ Hungary, H-9026 Györ, Egyetem tér 1. \\ E-mail: mgergo@sze.hu, koczy@sze.hu
}

\begin{abstract}
In historical district at European cities it is a major problem how to take decision on renovating or replacing existing buildings. This problem is imminent in Budapest (Hungary) in many traditional districts such as the Ferencváros district where we selected a compound area for further examination. By financial aid for the renovation of these buildings which awarded by Municipal Assembly of this district in question there is much uncertainty and confusion concerning how to decide whether or not and how to reconstruct a building where new private owners apply for support.

In this paper we propose a formal evaluation method based on fuzzy signature rule bases (the formal being a special case of L-fuzzy object). Using the available expert knowledge we propose a fuzzy signature model including relevance weights and weighted aggregations for each node and parent node, respectively, so that as a result a single membership value may be calculated for each building in question. Linguistic labels for decision (such as worthless, average, highly valuable, etc.) are generated from the values thus obtained. Such linguistic calculations might be of help for the Municipal Assembly awarding financial support. A complete example wit 26 buildings is presented.
\end{abstract}

Keywords: building condition evaluation, fuzzy signatures, weighted relevance aggregation operators.

\section{Introduction}

In the last twenty years due to the transition to democracy changes have happened in the property structure of building stocks, among others, in the Ferencváros ("Francis Town") district of Budapest (capital of Hungary) [1], [2]. The tendency of enhancing the role of private ownership resulted in difficulties of the maintenance process, since the expenses of a general intervention were multiples of the owners' capitals available. In practice, numerous external financial corporations are involved nowadays in supporting renovation and rehabilitation. This solution, however, increases the citizens' level of indebtedness and, consequently, influences the national debt harmfully.

For supporting renovation municipalities offer non-repayable direct financial assistance to the communities of flat owners. This financial aid is achievable annually by application: awarding is decided by the Municipal Assembly. The (non-financial) background of the decision on awarding consists mainly of urban aspects (façade and roof renovation), and is based at present exclusively on the data given by the applicant in the application form.

However these aspects are important and conform to public interest, numerous factors are disregarded and therefore the efficiency of the municipal financial assistance is challengeable. From the point of public view it may also be important to include other attributes of the given building, e.g. physical (static condition, energetic efficiency, etc.) and psychological (technical 
ageing, architectural, etc.) values. Based on further information an objective ranking of buildings may be created, which can help consider the condition of the applicants' buildings during the process of awarding.

In the present article a proposal for a decision-support tool is outlined that is based on a collection of technical information of the involved buildings. The attributes of buildings can be arranged in a predefined structure, where all information on the buildings can be evaluated systematically. Without any detailed explanation it is obvious that the goal (decision-support tool) and the circumstances (classified data structure, involvement of experts) strongly recommend the application of an expert system. Issuing from the character of data on hand and the observation methods applied, the expert system may well be based on fuzzy set theory [3], especially on the approach of fuzzy signatures which is an efficient tool for describing and characterizing objects with multiple and vague uncertain attributes.

\section{Professional Overview of the Examined Building Stock}

The Ferencváros district has four main residential areas. The Mid-part is located close to the city centre (see Figure 1).

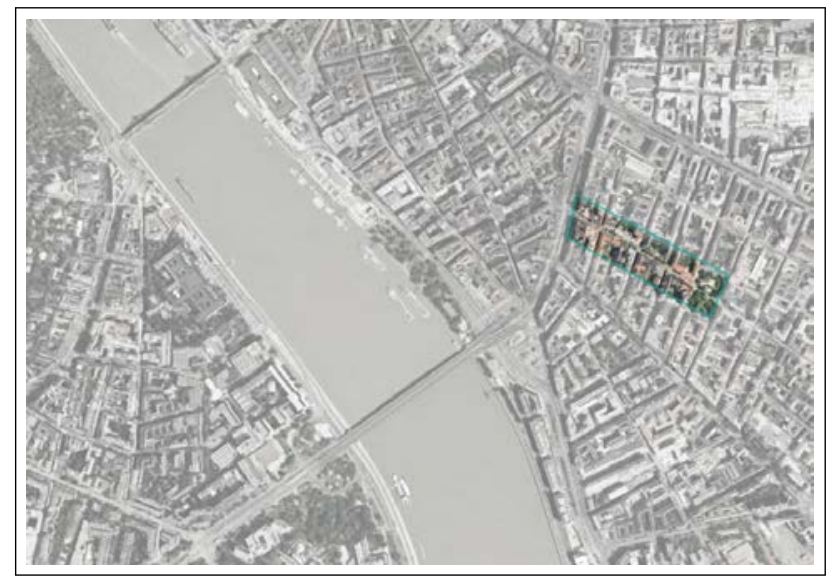

Figure 1: Overall view of the examined area (Middle Ferencváros)

The urban structure of this area was formed in the most effective period of urbanization in Budapest (1875-1920). The majority of the still existing apartment buildings were built in the first decades of the twentieth century or in the interwar period. Until the mid-nineties this district represented the slum area in the urban texture of the capital.

In the period of the '90s this area came into the attention of international urban designers and politicians by the expressed rehabilitation process. Among others the project manager SEM IX Municipal Company won the FIABCI Prize (a notable award of International Real Estate Federation) in the category of public sector in 1998. Beside the attractive intervention for renovating series of valuable buildings and public areas these changes caused serious relocation of citizens.

The main axis of the rehabilitated urban structure is the Tompa Street that links a busy traffic route (the Middle Ring Street) with a cozy and silent square in the centre of the district. At this semi-intensive area 26 apartment houses can be found on both sides of the $400 \mathrm{~m}$ long street. The overview of the area can be seen in Figure 2.

For introducing the apartment houses in the examined area it is worthwhile to describe the buildings by the age of construction. 


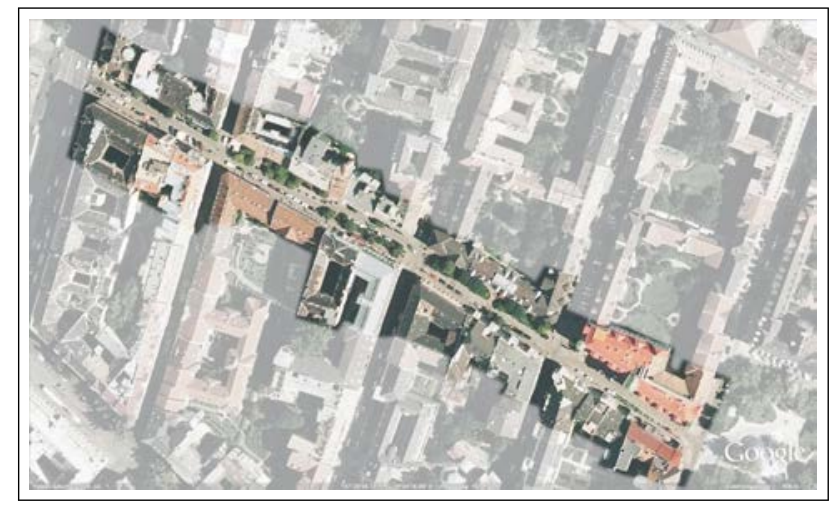

Figure 2: Tompa Street as the axis of a rehabilitation project

Two buildings (8\%) were built in the Age of Historicism (1875-1905, a period using various historical styles), although their constructions had been changed in the next periods. Therefore the global description of these buildings is given together with the next set of buildings.

The larger part of the buildings (14 pieces; 54\%) was constructed in the Age of Academic Style (1905-1920). The main attributes of these apartment houses (formerly rental houses) are collected in Table 1.

Three buildings were built in the interwar period (12\%) - those reflect to the Age of Modern with their attributes (see Table 2).

The rest (seven buildings; 26\%) was constructed during the rehabilitation period (1990-2004).

These apartment houses represent the attributes of this age (see Table 3).

The date of construction can be estimated by an overall look at the external architectural elements applied (cornices, decorations, etc.) and on the shape of the building. With the knowledge of the assortments of each period, a global description of buildings can be done.

However the collected attributes may represent the entire building stock in the examined area, it has to be remarked that every case is different. In Figure 3 a collection of different buildings represents the motley stock.

In spite of the rehabilitation project, some buildings remained in quite bad state with evidences of lack of maintenance (Fig.3a). In case of the larger part of the historic buildings only the façade was renovated (Fig. 3b). The poor energetic performance (see Table 4) and the natural ageing of associated building constructions (roof constructions, chimneys, waterproofing, etc.) may cause serious problems in the near future for the owners. Beside this, the setting of buildings, the application of narrow courtyards produces apartments with bad attributes (lack of sunlight in rear side apartments, badly ventilated courts, lack of vegetation, etc.).

Fig.3.c. represents a good example for good quality renovation and modernization at the same time: the two-storey building was enlarged with two more storeys and a penthouse with retaining the aesthetic values of the original building. In this case the transformation of the building resulted in good life circumstances (it received a common garden with the recently built adjoined block; only the well-orientated apartments were kept).

The buildings from the modern era (Fig 3e, 3f) are supposed to be in fairly good condition. However, although it is invisible outside, the reinforced concrete beams and pillars cause serious geometric thermal bridges (resulting in bad energetic attributes; even because of accumulation of vapor the appearance of mould on the interior surface of external walls is not excludable). It is also remarkable that the reinforced bauxite concrete load-bearing constructions need to be revised periodically (decennially).

The recently built apartment houses (Fig 3g, 3h) correspond to all regulations; the building 


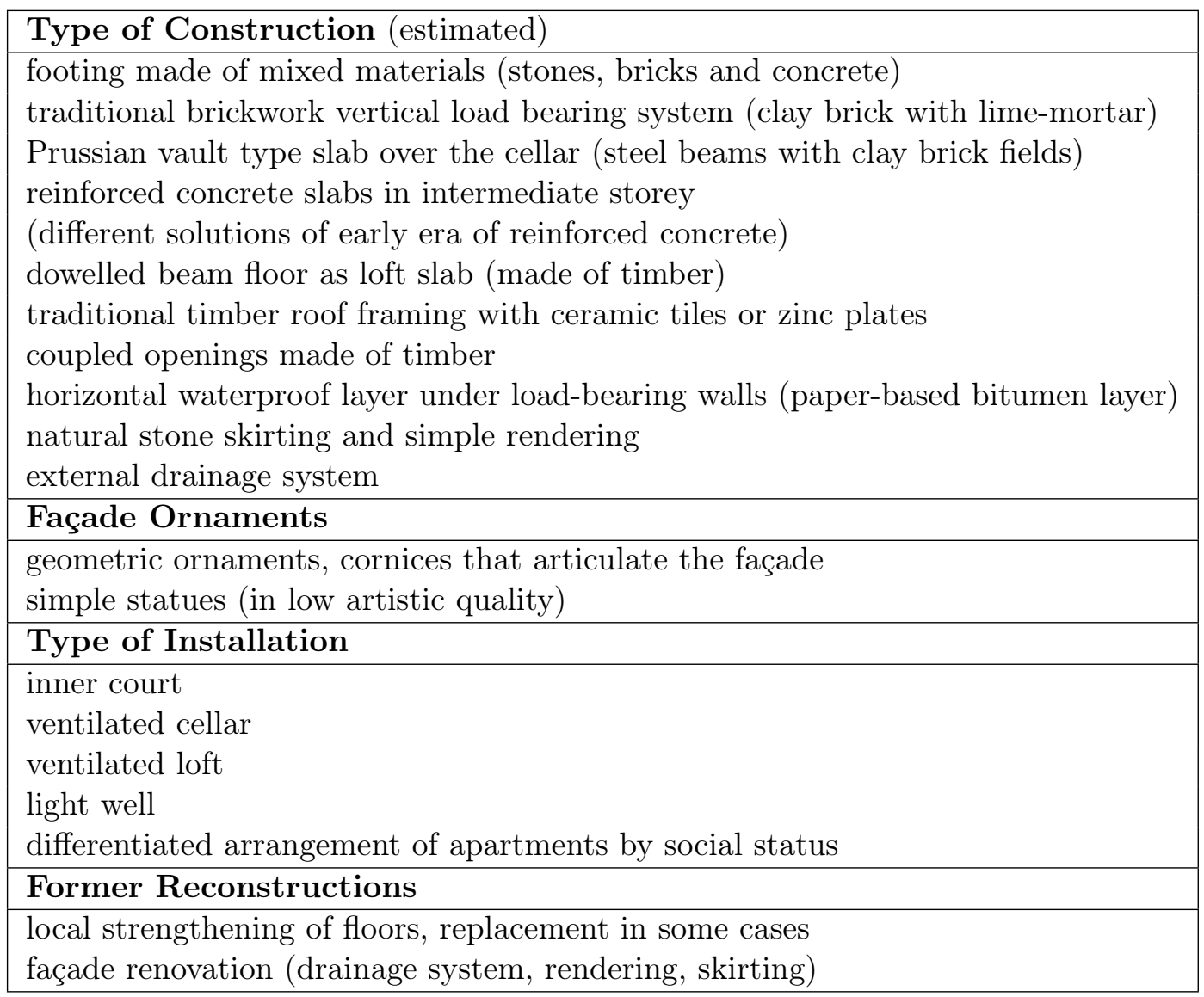

Table 1: Global attributes of rental houses built in period of $1875-1920$

\begin{tabular}{|l|}
\hline Type of Construction (estimated) \\
\hline pad footing made of concrete and stones \\
post and beam framework made of reinforced concrete with infilling brickwork wall \\
reinforced concrete slabs (in one case: utilization of bauxite as accelerating admixture) \\
flat roof with slag heat insulation and paper-based bitumen layer covering \\
coupled openings made of timber \\
waterproof layer under the entire building (paper-based bitumen layer) \\
natural stone skirting and simple rendering or natural stone cladding and brick façade \\
internal drainage system \\
\hline Façade Ornaments \\
\hline - \\
\hline Type of Installation \\
\hline integrated arrangement to an enclosed stairway \\
modern spatial structure with bright apartments \\
\hline Former Reconstructions \\
\hline flat roof reconstructions \\
façade renovation (broken stone replacements, rendering) \\
periodic revision of reinforced bauxite concrete structures \\
\hline
\end{tabular}

Table 2: Global attributes of apartment houses built in the interwar era 


\begin{tabular}{|l|}
\hline Type of Construction (estimated) \\
\hline footing made of concrete \\
post and beam framework made of reinforced concrete with infilling masonry unit \\
reinforced concrete slabs \\
heat insulated pitched roof with concrete tiles \\
plastic openings with insulated glazing \\
waterproof layer under the entire building (reinforced modified bitumen layer) \\
simple rendering \\
external drainage system \\
\hline Façade Ornaments \\
\hline simple and valueless decorations \\
\hline Type of Installation \\
\hline $\begin{array}{l}\text { integrated arrangement to an enclosed stairway } \\
\text { modern spatial structure with bright apartments }\end{array}$ \\
\hline Former Reconstructions \\
\hline - \\
\hline
\end{tabular}

Table 3: Global attributes of apartment houses built in the '90s

\begin{tabular}{|c|c|c|}
\hline & \multicolumn{2}{|c|}{ Heat Transmission Coefficient $\left(U\left[W / m^{2} K\right]\right)$} \\
\hline & $\begin{array}{c}\text { Mean values } \\
\text { (estimated) }\end{array}$ & current regulation \\
\hline External walls & 1.44 & 0.45 \\
\hline Loft slabs & 0.80 & 0.30 \\
\hline Openings & 2.80 & 1.60 \\
\hline
\end{tabular}

Table 4: Present energetic performance of former rental houses

constructions and the associated elements are supposed to be acceptable in quality. In spite of these facts, it has to be pointed out that the public interest could not be achieved here. From the aspect of cityscape these buildings are negligible.

\section{Application of Fuzzy Signatures}

In the case of the planned decision support tool the generalization of fuzzy sets first introduced by Zadeh [4] has to be mentioned; Zadeh's early student, Goguen proposed the concept of L-fuzzy sets [5]. L-fuzzy membership grades are elements of an arbitrary lattice L:

$$
A: x \rightarrow L, \forall x \in X
$$

Vector-valued fuzzy sets are introduced in [6]. They are special L-fuzzy sets, where L is the lattice of $\mathrm{n}$-dimensional fuzzy vectors, $\mathrm{L}=[0,1] \mathrm{n}$ in (1).

Vector valued fuzzy sets assign to each element of $X$ a set of quantitative features rather than a single degree - this way providing additional information about the specific element.

Fuzzy signatures [7] are generalized vector valued fuzzy sets, where each vector component is possibly another nested vector. This generalization can be continued recursively to any finite depth, thus forming a signature with depth $\mathrm{m}(2)$. 


$$
A_{s}: x \rightarrow\left[a_{i}\right]_{i=1}^{k}, a_{i}=\left\{\begin{array}{l}
{[0,1]} \\
{\left[a_{i j}\right]_{j=1}^{k}}
\end{array} \quad, a_{i j}=\left\{\begin{array}{l}
{[0,1]} \\
{\left[a_{i j}\right]_{l=1}^{k}}
\end{array} \quad, \forall x \in X\right.\right.
$$

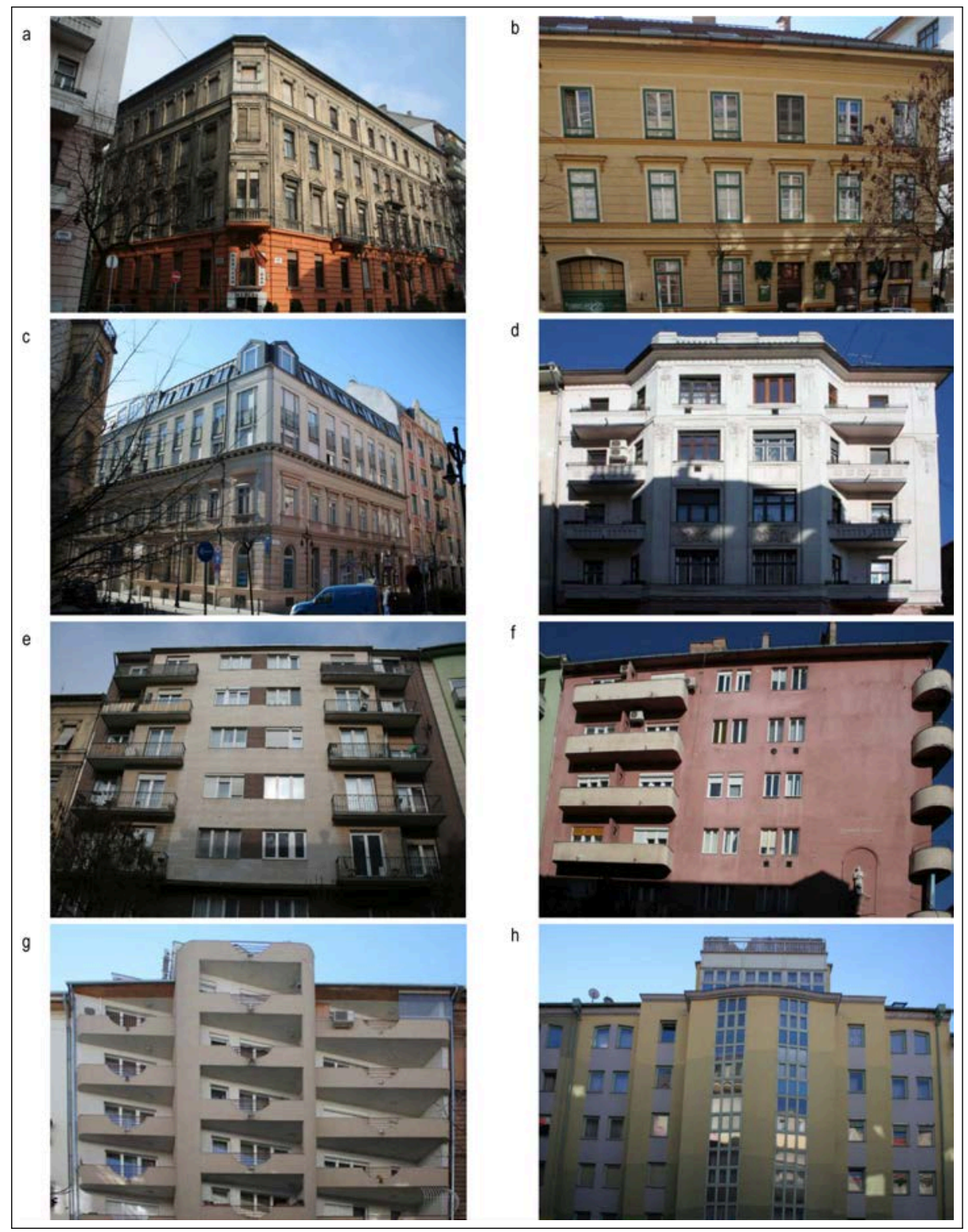

Figure 3: Representative buildings of the examined building stock

The structure of fuzzy signatures can be represented both in vector form and also as a tree graph (Figure 4 represents both the vector form and the tree graph of the proposed structure).

Fuzzy signatures can be considered as special, multidimensional constructions that are applicable for storing structured fuzzy data. In this structure the dimensions are interrelated in the meaning that a sub-group of variables determines a character on a higher level. Therefore, complex and interdependent data components can be described and evaluated in a compact way.

In many applications, the obtained information of experts can be described in different ways, even the structure of observation can be different; nevertheless decisions have to be taken by these data. With the assistance of signatures these alterations in structures can be handled. The 


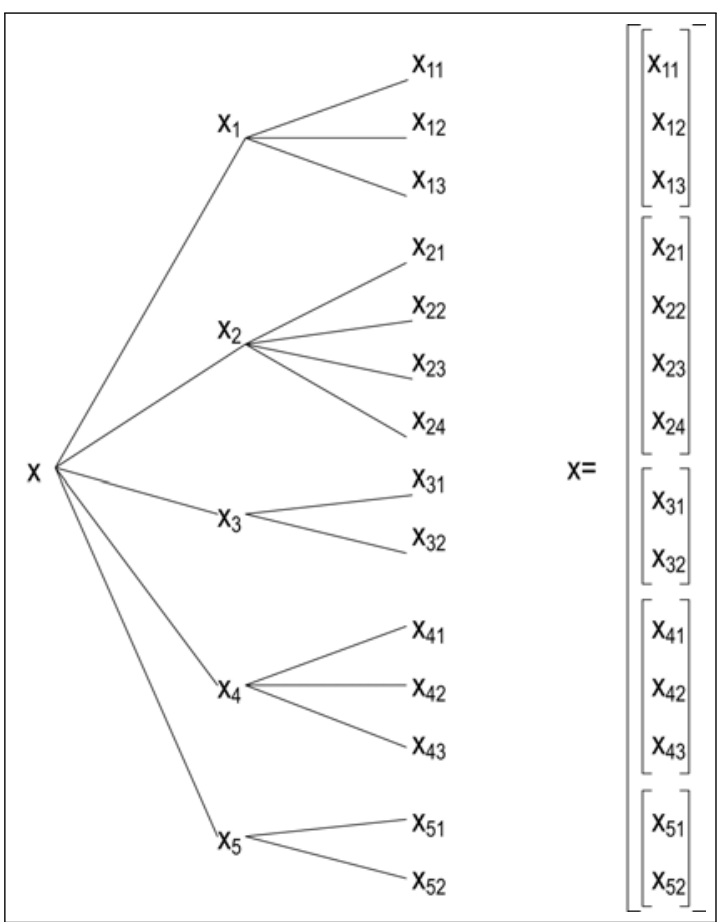

Figure 4: Tree structure and vector form of fuzzy signature

main advantage of the application of fuzzy signatures is that they can handle situations with uneven data structures and information.

Furthermore, the model created for the given task can be arranged hierarchically [8]; this feature is very similar to the way of thinking of human experts. This fact underlines the argument that fuzzy signatures are deployable on the area of decision making.

The advantage of fuzzy signatures is that they organize the available data components into hierarchical structures. This hierarchy determines the basic structure of fuzzy signature-based observations. It may occur that some elements are missing at several observations. Therefore, it is necessary to have a kind of structure modifier operator for comparing signatures with quite different structures. It is advisable to apply aggregation operators for reducing sub-trees to their parent node. In case of a multileveled hierarchy, a recursive process leads to obtaining the aggregated value of the parent node.

In our case, as the most important question the aggregation operators had to be defined. The structure of the fuzzy signature supports the use of different aggregation operators for each node.

\section{The Proposed New Approach}

As it was described in Section 2, due to several different aspects it is difficult to compare the elements of inhomogeneous building stock. This fact makes the judgements professionally unfounded in the awarding procedure presented in the introduction.

In the following a formal system will be proposed that may support the decisions of the Municipal Assembly in the awarding procedure. Similarly to [9], the proposed tool offers an effective solution for applying the experts' knowledge in responsible decision making. This system is based on fuzzy signatures described in Section 3.

In the recent decades the importance of visual examination on site increased in comparison 
with destructive analyses among building diagnostic experts. The shapes of the deteriorations, the information collected about checked building constructions and circumstances may offer enough evidence for experienced specialist to esteem the causes and consequences of building failures. Taking advantage of this, some new diagnostic tools were created (cf. Koppány, [10]).

As a comparable study, a comprehensive assessment of rental houses in Lisbon was compiled; furthermore, an objective evaluation of rental houses was done with a method based on visual examination on site [11].

The application of fuzzy set theory was proposed in bridge maintenance systems as well recently [12]. As Agárdy implies [13], soft computing techniques may help differentiating sets of objects of built environment by several aspects. As a decision support tool the fuzzy expert system was also proposed for determining the importance of intervention in case of building failures [14].

The circumstances of the evaluation of building stocks discussed above are quite different from the core problem of the above approaches. The methods of the assessments that were implied in the mentioned papers are applicable for examining the physical condition of the buildings and their elements without considering the narrower and wider context in their place. The aim of the present paper is to obtain a comprehensive and comparable data set for each building; therefore it was not possible to narrow the aspects to the physical and measurable conditions without losing important information.

This intent resulted in a large scale set of examination aspects that is difficult to handle without any classification abilities. This reason also explains why the adaptation of hierarchical system of fuzzy signature makes the support tool effective.

The model.

As the first step, the basic structure of the fuzzy signature developed from the available data and the experts' knowledge; then the adequate fuzzy sets of data elements must be determined. The next step is the identification of fuzzy signature based rules applying the experts' knowledge and the available input-output pairs. When the rule base is ready, the fuzzy signature based observation can be directly evaluated, thus generating a suggested decision.

Let us overview the concrete structure of the fuzzy signature suitable for representing the set of attributes and their respective relations used in the building evaluation approach.

In the context of this study the accessible information on a building may be arranged in five main groups, which groups constitute the first level of the fuzzy signature structure (nodes $\mathrm{x} 1$; $\mathrm{x} 2 ; \mathrm{x} 3 ; \mathrm{x} 4$ and $\mathrm{x} 5$ ).

For aggregating sub-trees within the fuzzy signatures the WRAO operator (Weighted Relevance Aggregation Operator, introduced by Mendis et al. [15]) was applied. With the application of weighted aggregations more expert knowledge can be involved in the examination. The initiated relevance weight determines the relevancy of a child node on a higher level. For determining the relevance weights by observation Mendis et al. [16] propose a method.

Let us denote the value and relevant weight of 1 child of $n$ pieces of aggregating nodes with $\mathrm{xl}$ and wl. The WRAO function is denoted with@ in (3).

$$
@\left(x_{1}, x_{2}, \ldots, x_{n} ; w_{1}, w_{2}, \ldots, w_{3}\right)=\left(\frac{1}{n} \sum_{l=1}^{n}\left(w_{l} \cdot x_{l}\right)^{p}\right)^{\frac{1}{p}}
$$

where the $p$ is the aggregator factor $\mathrm{p} \in \mathrm{R}, \mathrm{p} \neq 0$.

For describing different components of the structure linguistic variables may be applied. The next step is to define these linguistic variables and their membership functions.

The global analysis of apartment houses is a complex task. A large number of factors has to be considered while a building is evaluated. The goal of the discussed study was to obtain 
a comprehensive character of each building. Therefore, the parent nodes in the fuzzy signature structure are the five important segments of building sciences: urban planning (cityscape attributes); art and architecture (architectural quality); engineering (constructional quality); urban sociology (life quality) and protection of monuments (aesthetic attributes).

In the following the parent and child nodes are described in groups: their relevance weights are denoted with w. For the proper application of fuzzy set signatures it has to be confirmed that at the leaves membership functions shall be applied over the $[0,1]$ interval: for this reason the basic sets of the determined attributes have to be normalized to $[0,1]$. The closer the value of observation is to 1 the better is the quality in each respect.

At the nodes and at the leaves of the fuzzy signature structure partitions of triangular or trapezoidal sets are applied forming Ruspini partitions $[17]\left(\sum_{i} A_{i}\left(x_{0}\right)=1\right.$ for every $\left.x_{0} \in X[0,1]\right)$.

A. Cityscape Attributes $\left(x_{1} ; w_{1}=0.4\right)$.

The urban values of buildings are collected in the group of cityscape attributes. The matching of the examined building into the urban texture can be described by the following three child nodes (their membership functions are presented on Figure 5):

Matching to the character of the street $\left(x_{11} ; w_{11}=0.8\right)$ This attribute represents how the examined building harmonizes with the surroundings in shape, color, etc.

Matching to the position $\left(x_{12} ; w_{12}=0.4\right)$ This attribute represents how the relation is between the examined building and its position in the street (corner or other prevailing position).

Matching of the height of the façade $\left(x_{13} ; w_{13}=0.2\right)$ This attribute represents how the examined building differs from the surroundings vertically.

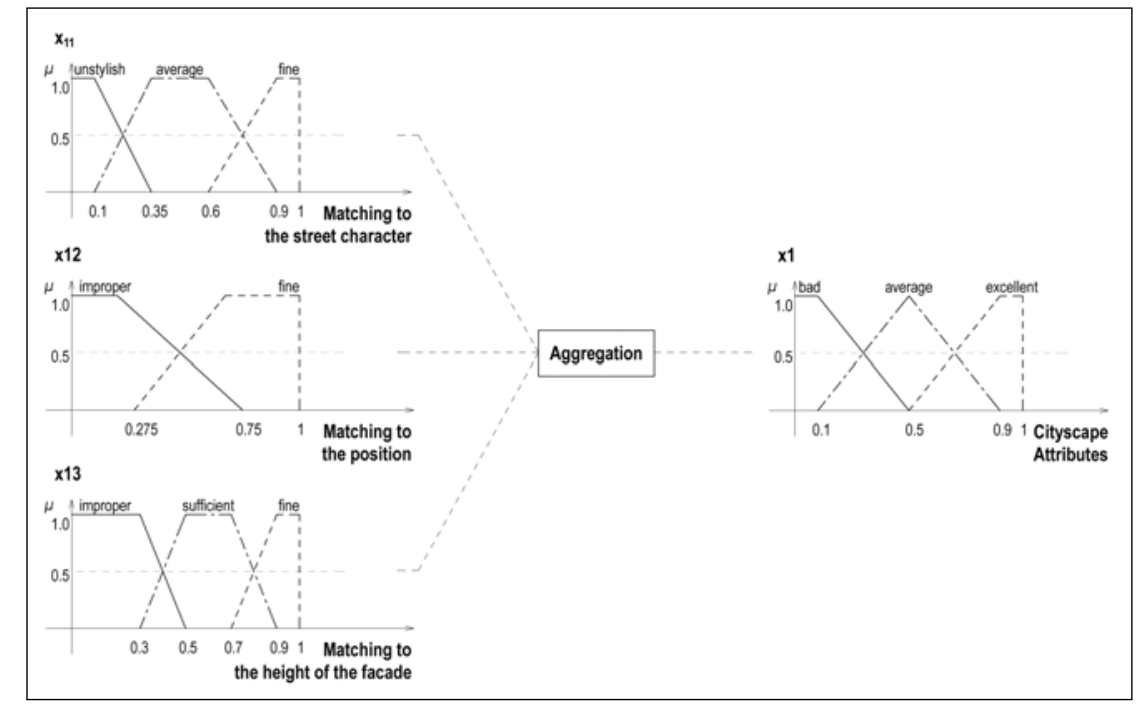

Figure 5: Membership functions of the Cityscape Attribute and of its child nodes

\section{B. Architectural quality $\left(x_{2} ; w_{2}=0.75\right)$.}

The broadly defined architectural quality represents the value of the building itself. As a product a building may represent extra meanings: it is more than a simple apartment house, it reflects the era of its design and construction. In this respect, four different attributes were established. The membership functions are presented in Figure 6.

Reproducibility $\left(x_{21} ; w_{21}=0.8\right)$ From the point of view of the reproducibility the buildings can be examined to what degree their construction could be realized with up-to-date technologies; considering available techniques and current regulations. In this case, mutatis mutandis, the lower value means that the given building is easier replaceable. 
Authenticity $\left(x_{22} ; w_{22}=0.3\right)$ This feature represents that how the examined building corresponds to the atmosphere of the age of its construction.

Value of in-built materials $\left(x_{23} ; w_{22}=0.4\right)$ The proper application of fine materials (e.g. natural stone, wrought iron, hand-manufactured bricks as claddings, etc.) increases the quality of the buildings. This feature represents in what rate the examined building contains additional attributes.

Body shaping $\left(x_{24} ; w_{24}=0.7\right)$ Although the architectural tools applied in design had changed during the ages, the plasticity of buildings was always important, even in the Age of Modern. Beside the plasticity it is also important whether the body shaping is in harmony with the surroundings.

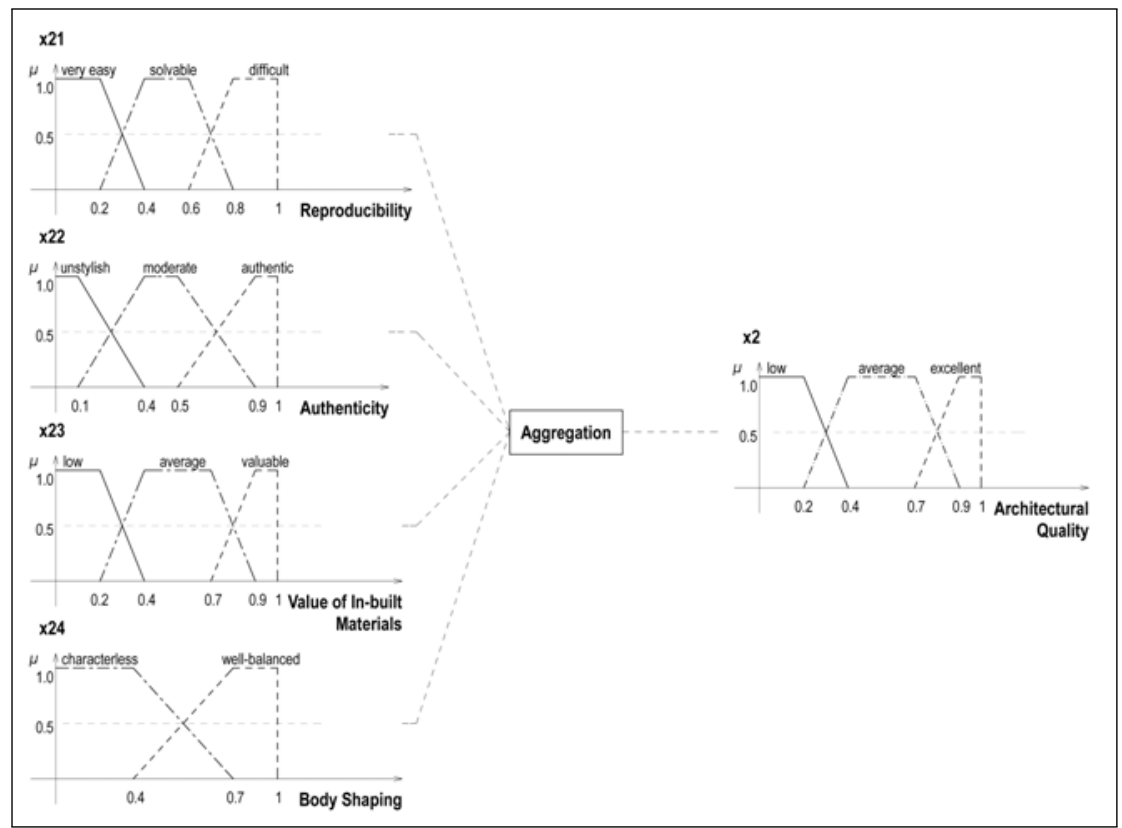

Figure 6: Membership functions of Architectural Quality and of its child nodes

\section{Constructional quality $\left(x_{3} ; w_{3}=0.85\right)$.}

The condition and the energetic performance of building constructions determine heavily the overall quality of the buildings. The exploring of the in-built constructions and their qualifying are done here only by visual examination on site. The discussed study does not contain a detailed and objective survey. The two components of this quality descriptor are as follows:

Consistence of building constructions $\left(x_{31} ; w_{31}=0.8\right)$ Although this fuzzy sub-signature can be divided into more sub-trees, here only single merged values are applied.

Energetic Attributes $\left(x_{32} ; w_{32}=0.4\right)$ The comparative analysis of external building constructions is based on estimated values for homogenous unit portions of the external wall, the openings and the loft slab. As a standard here the national regulations have to be also taken into account.

The values that represent the observations are not equal to the index number applied for determining the energetic quality of buildings.

D. Life quality $\left(x_{4} ; w_{4}=0.45\right)$.

This aspect has three components. Figure 8 represents the child nodes and the Life Quality membership functions.

Spatial arrangement of buildings $\left(x_{41} ; w_{41}=0.6\right)$ The spatial arrangement of flats may be concluded from the shape and the layout of the buildings. Although there can be a great variation of spatial arrangements of flats in a house itself, the type of the flats, the accommodation density 


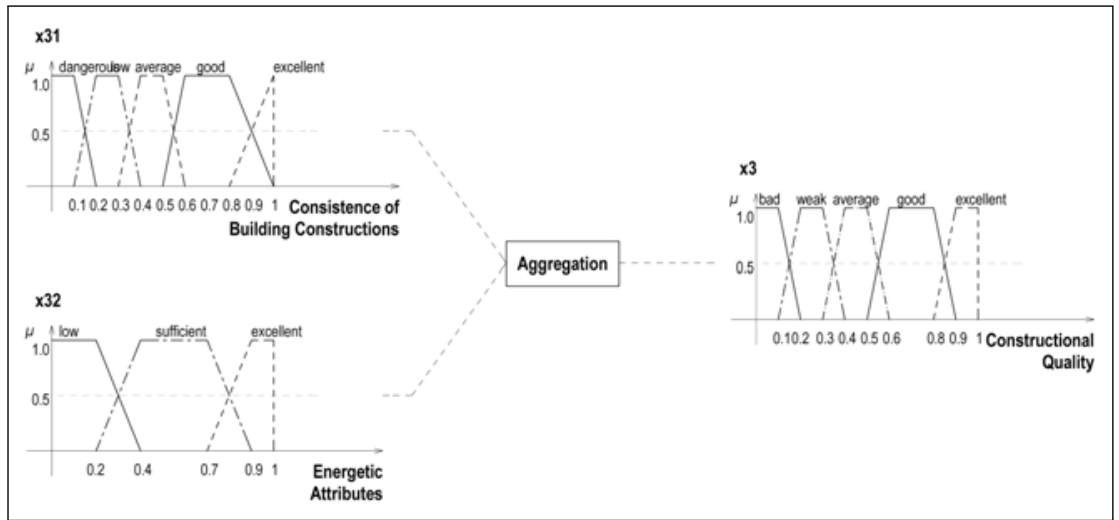

Figure 7: The Membership functions of Constructional Quality and of its child nodes

together determine the life quality of the examined building.

Existence of connection with private parks, gardens $\left(x_{42} ; w_{42}=0.4\right)$.

A part of the buildings have direct connection with private parks or gardens that influence the value of the building positively. The index that represents the existence of connection is binary (yes or no, 0/1).

Recreational quality $\left(x_{43} ; w_{43}=0.6\right)$ The distance of the examined buildings from the traffic route or the busy intersections influence the noise and pollution level of the interior spaces of the buildings. The recreational quality index represents this aspect as an accumulated value.

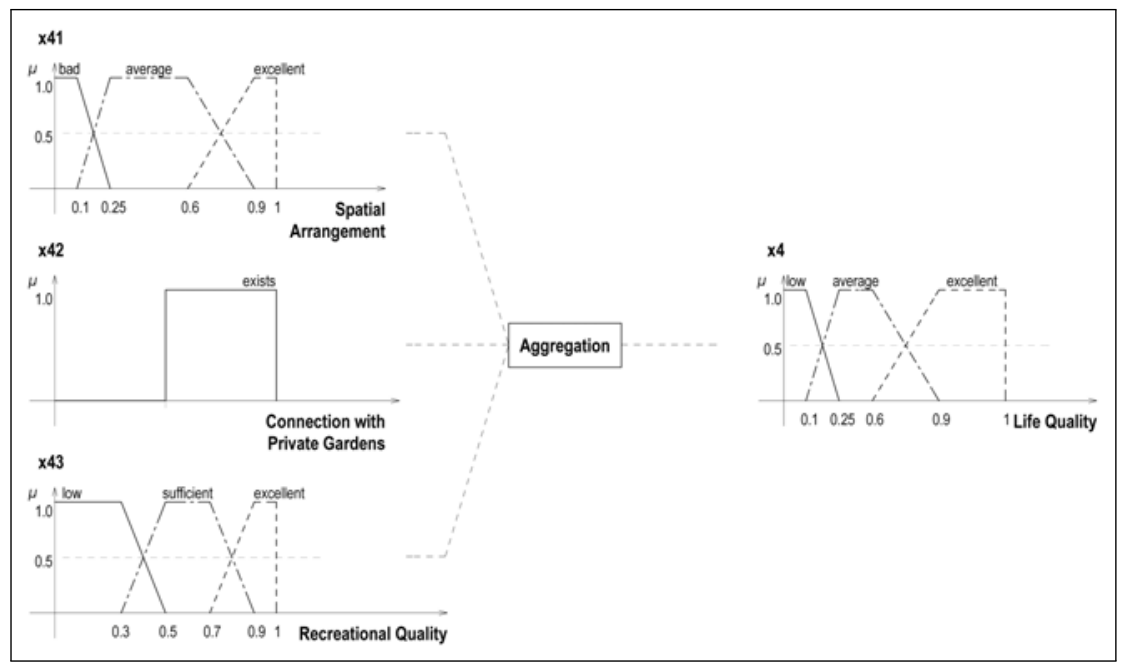

Figure 8: Membership functions of Life Quality and of its child nodes

E. Aesthetic Attributes $\left(x_{5} ; w_{5}=0.5\right)$.

Although the National Heritage Office has its professional tool for appreciating the historic value of buildings, in the present analysis only the external marks are taken into account. This attribute and its leaves can be seen in Figure 9.

Professional Judgement $\left(x_{51} ; w_{51}=0.8\right)$ The professional attributes of aesthetic evaluation are obtained from the analysis of the proportion of the buildings and the application of architectural elements. This analysis is founded on the qualification of the harmony between the design and the realization.

Public Judgement $\left(x_{52} ; w_{52}=0.3\right)$ For a comprehensive opinion about the examined buildings a public poll was done. 29 non-professionals filled questionnaires for representing the public opinion 
about the examined buildings. For evaluating the questionnaires a linguistic approximation according to [18] was applied. Some answers differed from the typical radically; the peaks and "needles" originating from this phenomenon were cut off ("noise cutoff").

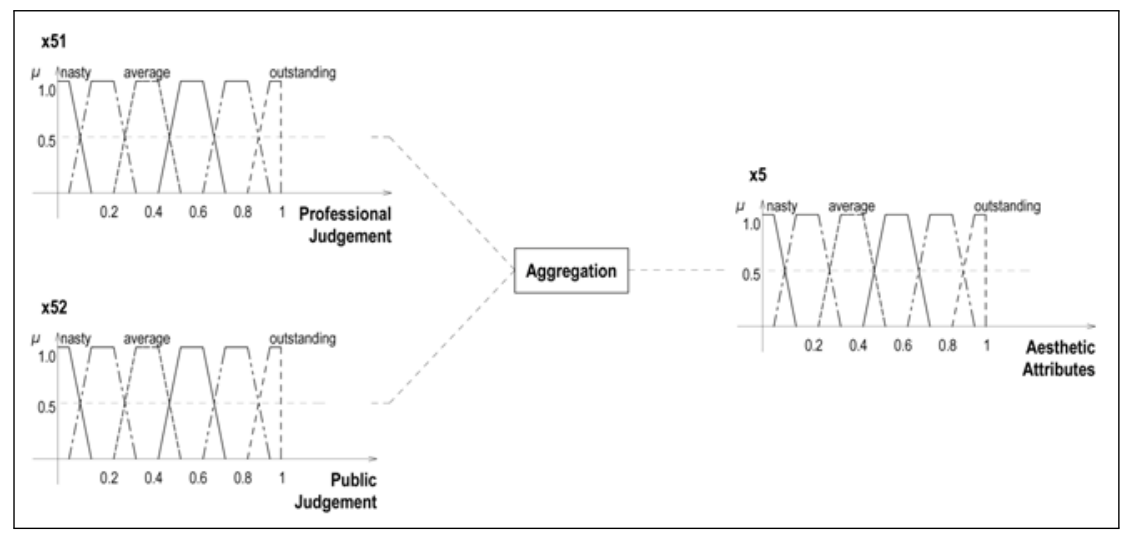

Figure 9: Membership functions of Aesthetic Attributes and of its child nodes

The Rule Base.

At the first level the number of available input variables is five. Their partitions $(3 ; 3 ; 5 ; 3 ; 6$ partitions) result that the total number of rules in the rule base is 810 . At the level of child nodes a different (much higher) number of rules can be identified from the partitions of input variables. The detailed description of these input variables and their partitions can be above. The hierarchical structure of the signatures presents dealing with a rule base of very high complexity.

Inference Method.

Basing on Mamdani-type inference [19], Tamás [20] introduced the generalized method that operates on signature based rule bases. In this method the alteration is only in the first step, where the degree of matching between observation and the antecedents of rules is determined.

In the discussed procedure this method is applied, where the minimum conjunction is taken as the aggregation operator for reducing the signature structure. Figure 10 represents the outline of a general fuzzy inference system.

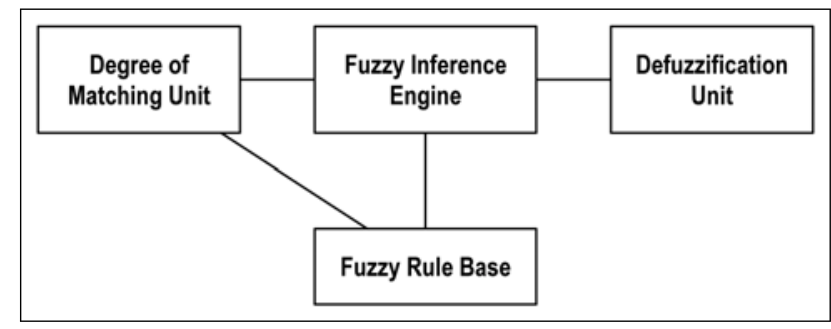

Figure 10: Outline of Fuzzy Inference Systems

\section{Results}

The examined buildings were evaluated with the method discussed above. The partial results are collected in Table 5 .

As an example the values obtained for building 17 in Fig $3 \mathrm{c}$ are presented here:

The result of fuzzy signature inference is a fuzzy set that can be defuzzified for determining the consequence value. In the present examination the COG (center of gravity) method was 


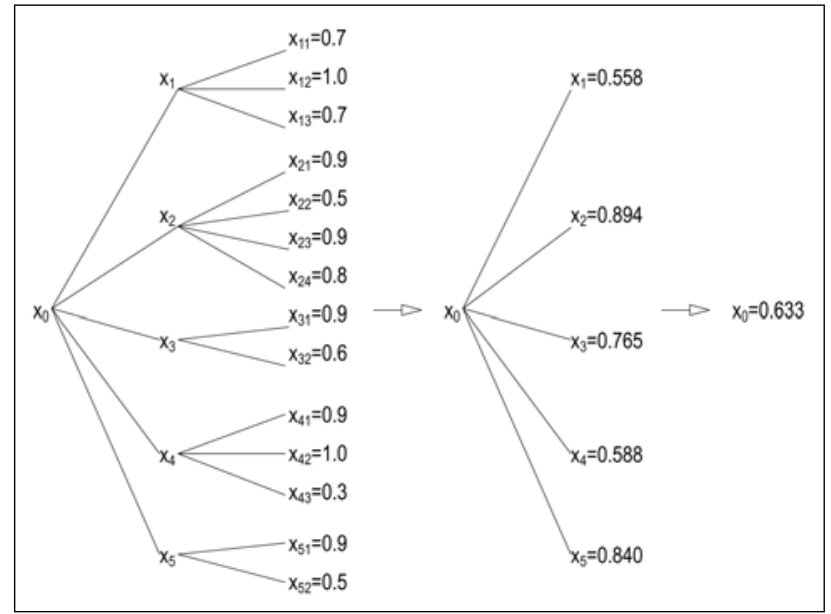

Figure 11: Fuzzy signature and aggregated values for building 17 (Fig. 3c)

\begin{tabular}{|c|c|c|c|c|c|c|c|c|c|c|c|c|c|c|c|c|c|c|c|c|}
\hline \multirow[b]{2}{*}{ (Na) } & \multicolumn{4}{|c|}{ Citcyacape Atta } & \multicolumn{5}{|c|}{ Architectural Quality } & \multicolumn{3}{|c|}{ Condray } & \multicolumn{4}{|c|}{ Lfe Quality } & \multicolumn{3}{|c|}{ A esthe6ic Atts } & \multirow{2}{*}{$\begin{array}{c}\text { Protection } \\
\text { Value } \\
\end{array}$} \\
\hline & $x_{n}$ & $x_{12}$ & $x_{13}$ & $x_{1}$ & $x=1$ & $x=$ & $x=$ & $x+4$ & $x_{2}$ & $x=1$ & $x_{2}$ & $x$ & $x_{1}$ & $x_{2}$ & $x_{0}$ & $x_{t}$ & xen & $x_{22}$ & $x_{s}$ & \\
\hline 5 & 0,9 & 0,9 & 0,9 & Q831 & 0,9 & 0,9 & 08 & 0,7 & 0,870 & 0,4 & 0,3 & 0,226 & 0,3 & 0,0 & 0,1 & 0,090 & 0,5 & 0,6 & 0,600 & 0,4540 \\
\hline 6 & 0,9 & 0,9 & 0,7 & Q831 & 0,8 & 0,8 & 0,4 & 0,8 & 0,710 & 0,3 & 0,2 & 0,128 & 0,3 & 0,0 & 0,1 & 0,090 & 0,7 & 0,8 & 0,700 & 0,3750 \\
\hline 7 & 0,5 & 0,8 & 0,9 & Q500 & 0,1 & 0,2 & 0.2 & 0,6 & 0,160 & 0,9 & 0,7 & 0,600 & 0,6 & 1,0 & 0.2 & 0,401 & 0,6 & 0,8 & 0,600 & 0,5000 \\
\hline 8 & 0,9 & 0,9 & 0,9 & Q831 & 0,5 & 0,5 & 0,6 & 0,6 & 0,550 & 0,4 & 0,4 & 0,250 & 0,4 & 1,0 & 0.2 & 0,102 & 0,5 & 0,5 & 0,500 & 0.2570 \\
\hline 9 & 0,4 & 0,9 & 0,9 & 0500 & 0,5 & 0,3 & 0,3 & 0,5 & 0,396 & 0,4 & 0,3 & 0,250 & 0,3 & 1,0 & 0,3 & 0,090 & 0,4 & 0,5 & 0,400 & 0,2600 \\
\hline 10 & 1,0 & 0,9 & 0,9 & Q831 & 0,2 & 0,5 & 0,5 & 0,6 & 0,474 & 0,4 & 0,3 & 0,250 & 0,6 & 1,0 & 0.2 & 0,401 & 0,5 & 0,6 & 0,500 & 0,4340 \\
\hline 11 & 0,9 & 0,9 & 0,5 & Q831 & 0,8 & 0,8 & 0,4 & 0,5 & 0,598 & 0,4 & 0,4 & 0,250 & 0,3 & 1,0 & 0,3 & 0,090 & 1,0 & 0,6 & 0,949 & 0,5000 \\
\hline 12 & 0,8 & 0,9 & 0,9 & Q656 & 0,7 & 0,9 & 0,4 & 0,8 & 0,62 & 0,3 & 0,3 & 0,185 & 0,6 & 1,0 & 0,3 & 0,401 & 0,7 & 0,9 & 0,700 & 0,4410 \\
\hline 13 & 0,8 & 0,9 & 0,7 & Q656 & 0,9 & 0,8 & 0,4 & 0,8 & 0,713 & 0,4 & 0,4 & 0,250 & 0,2 & 1,0 & 0,4 & 0,411 & 0,9 & 0,6 & 0,840 & 0,5000 \\
\hline 14 & 0,7 & 0,9 & 0,9 & Q555 & 0,8 & 0,4 & 0,4 & 0,4 & 0,550 & 0,3 & 0,3 & 0,185 & 0,2 & 0,0 & 0,3 & 0,100 & 0,7 & 0,6 & 0,700 & 0,3750 \\
\hline 15 & 0,5 & 0,8 & 0,7 & 4500 & 0,7 & 0,7 & 0,4 & 0,7 & 0,627 & 0,3 & 0,4 & 0,250 & 0,3 & 0,0 & 0,4 & 0,105 & 0,4 & 0,5 & 0,400 & 0,2500 \\
\hline 15 & 1,0 & 0,9 & 0,9 & Q831 & 0,5 & 0,3 & 0,5 & 0,6 & 0,431 & 0,5 & 0,3 & 0,250 & 0,5 & 1,0 & 0,4 & 0,411 & 0,8 & 0,6 & 0,800 & 0,5000 \\
\hline 17 & 0,7 & 1,0 & 0,7 & Q55B & 0,9 & 0,5 & 0,9 & 0,8 & 0,894 & 0,9 & 0,5 & 0,765 & 0,9 & 1,0 & 0,3 & 0,583 & 0,9 & 0,5 & 0,840 & 0,6330 \\
\hline 13 & 1,0 & 0,8 & 0,9 & Q831 & 0,7 & 0,7 & 0,5 & 0,8 & $0,62 \mathrm{~J}$ & 0,5 & 0,4 & 0,250 & 0,5 & 1,0 & 0,4 & 0,411 & 0,7 & 0,7 & 0,700 & 0,5000 \\
\hline 19 & 0,7 & 1,0 & 0,9 & Q55B & 0,9 & 0,2 & 0,8 & 0,7 & 0,609 & 0,4 & 0,3 & 0,250 & 0,3 & 0,0 & 0,3 & 0,090 & 0,8 & 0,8 & 0,800 & 0,5000 \\
\hline 20 & 0,3 & 0,9 & 0,9 & $Q 500$ & 0,3 & 0,2 & 0,5 & 0,7 & 0,423 & 0,5 & 0,3 & 0,250 & 0,7 & 1,0 & 0,4 & 0,411 & 0,5 & 0,4 & 0,500 & 0,3750 \\
\hline 21 & 0,9 & 0,7 & 0,7 & 9762 & 0,1 & 0,2 & 0,3 & 0,6 & 0,350 & 0,7 & 0,5 & 0,450 & 0,6 & 1,0 & 0,5 & 0,477 & 0,1 & 0,5 & 0,160 & 0,2500 \\
\hline 22 & 0,8 & 0,9 & 0,7 & Q656 & 0,9 & 0,9 & 0.2 & 0,5 & 0,550 & 0,2 & 0,3 & 0,185 & 0,8 & 1,0 & 0,3 & 0,388 & 0,9 & 0,2 & 0,700 & 0,4410 \\
\hline 23 & 0,2 & 0,9 & 0,8 & 9500 & 0,5 & 0,3 & 0,4 & 0,7 & 0,550 & 0,3 & 0,3 & 0,185 & 0,3 & 1,0 & 0,4 & 0,411 & 0,4 & 0,8 & 0,400 & 0,2500 \\
\hline 24 & 0,2 & 0,3 & 0,4 & Q386 & 0,1 & 0,1 & 0,5 & 0,7 & 0,153 & 0,8 & 0,5 & 0,450 & 0,8 & 1,0 & 0,3 & 0,388 & 0,1 & 0,6 & 0,160 & 0.2500 \\
\hline 25 & 0,2 & 0,5 & 0,2 & Q381 & 0,1 & 0,2 & 0,3 & 0,8 & 0,398 & 0,5 & 0,6 & 0,250 & 0,4 & 1,0 & 0,4 & 0,411 & 0,2 & 0,3 & 0,200 & 0,2500 \\
\hline 25 & 0,3 & 0,6 & 0,4 & Q437 & 0,2 & 0,1 & 0,3 & 0,8 & 0,398 & 0,9 & 0,5 & 0,600 & 0,8 & 1,0 & 0,5 & 0,467 & 0,2 & 0,3 & 0,200 & 0,2500 \\
\hline z & 0,3 & 0,7 & 0,3 & Q470 & 0,1 & 0,2 & 0,3 & 0,8 & 0,393 & 0,5 & 0,8 & 0,525 & 0,5 & 1,0 & 0,5 & 0,477 & 0,2 & 0,3 & 0,200 & 0,2500 \\
\hline 28 & 0,2 & 0,5 & 0,7 & Q392 & 0,1 & 0,1 & 0,3 & 0,6 & 0,174 & 0,8 & 0,5 & 0,450 & 0,7 & 1,0 & 0,4 & 0,411 & 0,1 & 0,3 & 0,160 & 0.2500 \\
\hline 2 & 0,8 & 0,8 & 0,8 & Q627 & 0,7 & 0,3 & 0,4 & 0,4 & 0,459 & 0,3 & 0,3 & 0,185 & 0,3 & 1,0 & 08 & 0,482 & 0,4 & 0,6 & 0,400 & 0,3360 \\
\hline 30 & 0,1 & 0,1 & 0,2 & Q169 & 0,1 & 0,1 & 0.2 & 0,8 & 0.153 & 0,8 & 0,7 & 0,450 & 0,7 & 1,0 & 08 & 0,571 & 0,1 & 0,6 & 0,160 & 0.2500 \\
\hline
\end{tabular}

Table 5: Evaluation of the examined buildings 
applied.

The applied categories for the assessment of buildings at the side of consequence are visible in Table 6 where the categories and corresponding ranges of values for the ranked buildings are presented.

\begin{tabular}{|c|c|c|}
\hline Categories & Values & Buildings (Nr.) \\
\hline worthless & $0-19 \%$ & \\
\hline below average & $20-39 \%$ & $6 ; 8 ; 9 ; 14 ; 15 ; 20 ; 21 ; 23 ; 24 ; 25 ; 26 ; 27 ; 28 ; 29 ; 30$ \\
\hline average & $40-74 \%$ & $5 ; 7 ; 10,12 ; 13 ; 16 ; 17 ; 18 ; 19 ; 22$ \\
\hline valuable & $75-89 \%$ & \\
\hline highly valuable & $90-100 \%$ & \\
\hline
\end{tabular}

Table 6: Categories of overall value of the examined buildings

The result of the evaluation demonstrates that the building stock has a balanced value. In spite the fact that each building has different conditions (age, aesthetical, constructional quality), the deviation among their category indices is low. Among other conclusions this result may confirm the perception that the buildings constructed recently did not increase the overall value of the examined building stocks.

\section{Conclusions and Future Work}

As a summary it can be stated that the results of calculations correlate to the former assumptions. The utilization of linguistic variables supported the evaluation of non-measurable (e.g. aesthetic) and uncertain (e.g. energetic performance) values. The application of weighted relevance aggregators in the reducing phase also maintained the professional aspects in examination. The unique hierarchical construction of fuzzy signature structure enhanced the adequacy of the overall evaluation. These statements certify the previously expressed supposition that a complex and well defined decision support tool based on fuzzy signature structure may help in the mentioned awarding procedure.

Therefore, after several refinements of the tool, it is going to be presented to the Municipal Assembly. These refinements may take place in a further research project in the following directions.

The complexity of the building (different structural and sub-structural components, spatial object with complicated relation to the users and the surroundings, etc.) requires more complex analyses. That is why it is necessary to increase the number of attributes and to create more precise linguistic variables. For avoiding the confusion in the system in the process of the enlargement of the structure it is advisable to create further sub-trees (sub-sub-trees).

It is also worth considering that a confidence index can be involved for the process of determination of the matching the rules that may support differentiating the observations.

The developed decision support tool may take the intermittently determined aspects of the Assembly. Therefore the application of controllable relevance weight on the parent nodes has to be examined.

\section{Acknowledgement}

The authors wish to record their gratitude to Attila Koppány for his advices and professional assistance during each phase of the project. 


\section{Bibliography}

[1] G. Locsmándi, Large-Scale Restructuring Processes in the Urban Space of Budapest, in R. Dalla D. Longa (ed.) Urban Models and Public-Private Partnership, Berlin, Springer Berlin Heidelberg, 2011

[2] S. Lowe, A tale of two cities - rental housing in Budapest and Sofia in the 1990s, Journal of Housing and the Built Environment, Kluwer Academic Publishers, pp. 249-266, 2000

[3] L. T. Kóczy and D. Tikk, Fuzzy Systems (in Hungarian), Budapest, Typotex, 2000

[4] L. A. Zadeh. Fuzzy Sets, Information and Control, 8, pp. 338-353, 1965

[5] J. A.Goguen, L-Fuzzy Sets, Journal of Mathematical Analysis and Applications, 18, pp. 154-174, 1967

[6] L. T. Kóczy, Vector Valued Fuzzy Sets, BUSEFAL, Tolouse, pp. 41-57, 1980

[7] L. T. Kóczy, T. Vámos, G. Biró, Fuzzy Signatures, Proceedings of EUROFUSEC-SIC'99, Budapest, pp. 210-217, 1999

[8] K. W. Wong, A. Chong, T. D. Gedeon, L. T. Kóczy, Hierarchial Fuzzy Signature Structure for Complex Structured Data, Proceedings of the International Symposium on Computational Intelligence and Intelligent Informatics, Nabeul, Tunisia, pp. 105-109, 2003

[9] I. Anica-Popa, G. Cucui, A Framework for Enhancing Competitive Intelligence Capabilities using Decision Support System based on Web Mining Techniques, International Journal of Computers Communications \& Control, ISSN 1841-9836, 4(4):326-334, 2009

[10] A. Koppány, A Diagnostic System Created for Evaluation the Quality of Building Constructions, Proceedings of 11 DBMC International Conference on Durability of Building Materials and Components, Istambul, 2008

[11] C. O. Pedro et al., Portuguese Method for Building Condition Assessment, Emerald, Lisbon, 26, pp. 322-335, 2008

[12] I. Szaradics, Adaptability of Fuzzy Control Systems in Bridge Management (M.Sc thesis), Györ, Széchenyi István University, 2007

[13] Gy. Agárdy, Fuzzy Logic Techniques in Bridge Management Systems, Acta Technica Jaurinensis, Gyôr, Széchenyi István University, 1, pp. 49-60, 2008

[14] G. I. Molnàrka, The Construction of the Knowledge Base of Fuzzy Expert System in Building Pathology - From a Functional Access, Proceedings of CIB World Building Congress, Rotterdam, pp. 1406-1417, 2007

[15] B. S. U. Mendis, T. D. Gedeon, J. Botzheim, L. T. Kóczy, Generalised Weighted Relevance Aggregation Operators for Hierarchical Fuzzy Signatures, Proceedings of the International Conference on Computational Intelligence for Modelling, Control and Automation (CIMCA 2006), Sydney, 2006

[16] B. S. U. Mendis, T. D. Gedeon,L. T. Kóczy, On the Issue of Learning Weights from Observations for Fuzzy Signatures, Proceedings of the World Automation Congress 2006, Budapest, pp. 1-6, 2006 
[17] E. H. Ruspini, A New Approach to Clustering, Information Control, 15, pp. 22-32, 1969

[18] A. Mehler, K. Reinhard, G. Klir, K. Sentz, On the Issue of Linguistic Approximation. Aspects of Automatic Text Analysis, Studies in Fuzziness and Soft Computing, Berlin, Springer Berlin, Heidelberg, 209, pp. 61-78, 2007

[19] E.H.Mamdani, S.Assilian, An Experiment in linguistic variables with a fuzzy logic controller, International Journal of Man Machine Studies, 7, pp. 1-13, 1975

[20] K. Tamás, L. T. Kóczy, Mamdani-type Inference in Fuzzy Signature Based Rule Bases, 8th International Symposium of Hungarian Researchers on Computational Intelligence and Informatics, Budapest, pp. 513-525, 2007 